\title{
Fully automated vehicles: the use of travel time and its association with intention to use
}

\section{Zia Wadud PhD}

Associate Professor, Institute for Transport Studies \& School of Chemical and Process Engineering, University of Leeds, Leeds, UK

(corresponding author: z.wadud@leeds.ac.uk)

(Orcid:0000-0003-2692-8299)
Fuad Yasin Huda MSc

Senior Lecturer, Department of Civil Engineering, East West University, Dhaka, Bangladesh

Traditionally, time spent travelling has been seen as a 'cost' to the traveller. Autonomous or fully automated vehicles (FAVs) can free the driver of the driving task and allow engagement in other worthwhile activities inside the FAVs, which can transform how people travel. However, there is little understanding about how travel time can be used and how worthwhile this time can be in FAVs; and whether this is related to the intention to use FAVs. This paper addresses these questions through a multi-country questionnaire survey, with a sub-sample of chauffeur-driven car users to mimic time use in FAVs. Responses show that users are likely to engage in other non-driving activities while riding in FAVs, and these differ according to trip purpose and direction. Time spent travelling in FAVs is perceived to be more useful than in current modes of transport. Interest in using FAVs is directly correlated with perceived usefulness of time in autonomous vehicles. There is a strong correlation between intended activities in FAVs and current activities by primary car users in chauffeur-driven cars, providing some validation to the stated intention responses. Results have important implications for policy-making, time use and value-of-time research, as well as vehicle interior design.

\section{Notation}

$\boldsymbol{X}_{i} \quad$ vector of explanatory factors

$Y_{i} \quad$ probability of a response

$y_{i}^{*} \quad$ unobserved continuous variable

$\alpha \quad$ parameter (constant)

$\boldsymbol{\beta}$ parameter vector

$\varepsilon_{j} \quad$ errors

$\tau_{j} \quad$ threshold values

\section{Introduction}

Fully automated vehicles (FAVs), where a vehicle can drive itself from an origin to a destination without any human driving input, have received enormous attention from the media, members of the public and transport researchers since Google's (now Waymo) first public demonstration of such a car in 2012. The UK's Department for Transport (DfT, 2015a) identified four key benefits from these self-driving, driverless or autonomous vehicles: (a) creating more free time (inside the vehicle); (b) improving safety; $(c)$ easing congestion and reducing emissions; and $(d)$ increasing access to vehicles. Understanding and quantifying these impacts is a growing area of research, and this paper focuses on the first of these by investigating the potential implications of travel time use in FAVs, which has not received any attention in the literature before.

In the literature relating to transport economics and appraisal, travel time is viewed to cause a disutility (Mokhtarian and Salomon, 2001) - in other words, the time during travelling is a 'cost' to the traveller, and this cost is considered in users' mode choice decisions and in transport project appraisal. An FAV, however, is expected to allow the traveller to engage in other worthwhile activities and thus create 'free time' that would otherwise have been used in driving the vehicle (Wadud et al., 2016; Wardman and Lyons, 2016). To this end, KPMG (2015) estimates that the benefits of using the freed-up driving time productively can be quite large (up to $£ 20$ billion) to the UK economy. The willingness to pay for these vehicles is also likely to depend on how useful the travel time can be in FAVs (Bansal et al., 2016). Despite the acceptance that the freed-up travel time in an FAV can be used to engage in different activities and the importance of the travel time costs for demand forecasting and appraisal, there is little understanding of how people would spend their time in FAVs, and how useful or worthwhile that time is likely to be. Also missing is any revealed evidence on how travel time is currently used in cars, which could be used to anchor the results of potential future use in FAVs.

The aim of this research is to address the gap by investigating the (possible) link between current travel time use in cars, the potential usefulness of travel time in FAVs and its effects on the intention to use FAVs. To address this, several interlinked research questions are investigated

(a) whether there is any evidence of primary car users utilising their travel time currently by engaging in activities on board the car and what those activities are

(b) how people intend to engage in different activities while travelling in FAVs in future and whether there are any differences in their intended use depending on the purpose or direction of the trip

(c) whether there are any similarities between the activities people engage in while they are in a car now (from point (a)) and intended activities in an FAV (from point $(b)$ ) 
(d) whether and how people perceive the potential usefulness of their travel time in FAVs and what factors - especially the possibility of motion sickness - affect this perceived usefulness

(e) whether the interest in travelling in FAVs is associated with the perceived usefulness of travel time.

Except for cursory exploration of the second objective, no other studies have investigated these important questions related to travel time use in the context of FAVs. The paper is organised as follows. Section 2 presents the literature around the disutility of travel time and how it can be usefully spent in some transport modes, along with a summary of the small amount of literature on the use of travel time in FAVs. Section 3 describes the survey process to collect the data and explains why studying chauffeur-driven car users is important in this context. Section 4 analyses the data, presents the results and discusses these in the context of the broader literature. Section 5 draws conclusions.

\section{Relevant literature}

\subsection{Multitasking and (dis-)utility of travel time}

The practice of viewing travel time as a 'cost' is central in transport economics - both in appraisal of transport-related projects and in travel-related decision-making (e.g. mode choice, route choice, etc.) - and has been well established for decades. According to this literature people benefit from being physically present at a destination: travelling there is only a means to that end and therefore the demand for travel is a 'derived' demand (Mokhtarian and Salomon, 2001). The time spent during travelling is a source of disutility for two reasons (Ettema and Verschuren, 2007): first, travel time is a 'loss' or 'waste' that could have been spent in conducting other worthwhile activities; second, the act of travelling itself can be tiring or stressful. In transport project appraisal, travel time constitutes one of the largest components of transport costs and thus reducing travel time is often the most important goal in transport improvement projects (Frei et al., 2015). In the same vein, a faster transport mode is more attractive compared to a slower one, as long as the other characteristics of the modes are similar. The value of time (VOT) or the value of travel time saved (VTTS) are thus important metrics, and the valuation of travel time is a well-established area in transport economics research.

In a seminal work, Mokhtarian and Salomon (2001) argue that travel time could provide a positive or less negative utility if other activities can be carried out during travel (e.g. reading, relaxing, working, etc.). This possibility has received attention from researchers in the form of 'travel time use' or 'multitasking', with clear evidence using multiple methods (questionnaires, direct observations, modelling) that travellers are increasingly using their travel time doing something worthwhile, which can reduce the disutility of travel. Jain and
Lyons (2008) suggest the existence of two types of 'gift' of time during travel: 'transition' time prepares travellers for their destination, while 'time out' time allows them to escape from obligations and relax. Mokhtarian and Salomon (2001) and Redmond and Mokhtarian (2001) also suggest that there is an optimal commute time of about 15 to $20 \mathrm{~min}$, hinting at the existence of a net positive utility of travel time - at least in some circumstances, such as during a commute.

The travel time valuation literature recognises these propositions and suggests that the VOT or VTTS is unique to everyone and varies depending upon socio-economic characteristics as well as trip purpose, trip length, travel mode, convenience, crowding (if public transport) or the presence of others (in a car) and other environmental factors (e.g. in the UK VTTS for commuting and business trips are $£ 5 \cdot 08 / \mathrm{h}$ and $£ 22 \cdot 74 / \mathrm{h}$, respectively (DfT, 2015b)). In addressing the possible worthwhile use of travel time, Mackie et al. (2003, p. 50) suggest 'the opportunity to use travel time productively can be expected to impact on the value of time, and in this respect the advent and widespread ownership and use of mobile phones and the possibility to use laptop computers on some mode may have had a significant downward influence on the value of time'. Indeed, nearly all of the empirical evidence shows that the opportunity to use travel time usefully reduces the negative utility of travel (e.g. Batley et al. (2010) for the UK; and Ettema and Verschuren (2007) and Significance et al. (2012) for the Netherlands). The accepted principle still is that the utility of travel time remains negative, but is less so when other activities can be pursued together, which is what Rasouli and Timmermans (2014) indeed show using a regression framework for estimating travel time utility.

A different strand of literature specifically investigates how travellers use their time during travel (e.g. Gamberini et al., 2012; Guo et al., 2015; Lyons et al., 2007; Ohmori and Harata, 2008; Susilo et al., 2012; Timmermans et al., 2002; van der Waerden et al., 2009; Zhang and Timmermans, 2009). Lyons et al. (2007) and Susilo et al. (2012) conducted possibly two of the largest questionnaire surveys on rail passengers' use of time in the UK in 2006 and 2010. The share of respondents engaged in different activity types was remarkably similar in each of the two surveys. Susilo et al. (2012) also model the 'utility' derived from travel time use in trains, although they do not directly relate that to VTTS.

Nearly all of the literature on the use of travel time focuses on public transportation modes (see e.g. Keseru and Macharis (2018) for a review). Very few studies investigate the useful use of travel time during car travel and even these studies are limited to qualitative observations. This is not unexpected: the majority of car trips (especially commutes, which have received the most attention so far) in the developed world are single occupancy, where the traveller is also driving the car. Since driving requires nearly the full attention of the driver all of the 
time, there are limited opportunities to engage in other useful activities (except passive activities such as listening to music/radio), which makes the questionnaire style surveys conducted for train or bus passengers less useful in this context. Nonetheless, Basmajian (2010) investigated how parents catch up with their children and prepare for work and home chores during driving to and from work, or prefer the 'time out' time. Laurier (2004) described in detail the work done by a female executive while driving. Hislop (2013) reports that over half of his sample of business travellers used a phone for work purposes while driving. This aspect of willingness to 'multitask' during driving or travelling is clearly highly relevant to FAVs, given they will allow the 'drivers' to engage in other worthwhile activities, without compromising safety.

\subsection{Travel time use and mode choice}

The choice between using cars and public transport modes is always a trade-off. The car provides flexibility, autonomy, comfort and privacy - all of which are desirable - but it does not allow drivers to make productive use of their driving time. Public transport modes - especially trains - allow productive use of travel time on board, which is highly desired, but they are often inconvenient, uncomfortable, have a rigid schedule and do not provide any privacy. At any point in time or in a country or a city, the modal split between road and rail travel reflects this trade-off by the travel decision-makers. The literature on the effect of the ability to multitask on this mode choice trade-off is sparse, although the growth in rail travel in the UK over the last decade has been partially attributed to the mode's ability to allow people to make good use of their travel time - especially for business trips (Wardman and Lyons, 2016). Malokin et al. (2015) also show that the ability to multitask in public transport modes affects the choice of travel modes in the USA, while Ettema et al. (2012) report that the satisfaction of public transport modes depends on multitasking possibilities while riding.

Full vehicle automation is likely to alter radically the existing state of this trade-off in mode choice decisions, since the driving tasks are removed from the driver in such a vehicle, offering them the opportunity to engage in other worthwhile activities. This removes a key disadvantage of driving private vehicles and thus will likely encourage the use of fully automated cars at the expense of public transport modes (Wadud et al., 2016; Wardman and Lyons, 2016). The activities to be engaged in FAVs will also alter the utility of travel time and thus reduce the VTTS (Le Vine et al., 2015; Wadud et al., 2016), which is a key component in mode choice modeling, as well as transport project appraisal. As such it is important to know more about how people could use their driving time in FAVs and how useful that use is.

\subsection{Use of travel time in FAVs}

Several recent studies have investigated the potential use of travel time in a future driverless car. These include Schoettle and Sivak (2014), Cyganski et al. (2015), Kyriakidis et al. (2015) and Bansal and Kockelman (2017). Table 1 presents the summary findings of three of these surveys (Cyganski et al. (2015) could not be converted to this format, as the style of questions was different). It is clear that potential users of FAVs show an inclination to engage in different types of activities that are worthwhile to them. Notably, all three studies are about wider consumer perceptions related to FAVs, hence the questions and the analysis are not as detailed as those used for the literature on time use and multitasking mentioned earlier. Often, the surveys contain only one question about how the riders may use their travel time in an FAV, with no attempts to differentiate potential use by journey type, direction of travel or duration of travel. Also, none of these studies focus on how driving time is used in a car now, although Kyriakidis et al. (2015) attempt to reveal the 'potential' time use in a manually driven car. However, they do not clearly ask how the respondents currently use their time while driving, but rather ask about the 'intention' to use time in a manually driven car. A relatively high share of responses $(\sim 10 \%)$ indicated potential participation in 'active' secondary tasks (e.g. reading, watching movies, sleeping/resting etc.) while driving manually, which raises some concern. This underlines the value of investigating not only how people may potentially use their travel time in an FAV, but also some validation of that intention through a some evidence on how they use time in a car currently when not driving.

\section{Methods and data}

\subsection{Survey and data collection}

Given FAVs are still not available to users, the previously mentioned surveys on the use of travel time on board FAVs are all 'stated intention' in nature, with hypothetical questions about how people might spend their time in these vehicles. Asking existing drivers about their 'revealed' use of driving time will clearly underestimate the potential future use in automated vehicles because current drivers are primarily engaged in driving and can become involved only in passive activities. Although it is possible to ask only car passengers about their travel time use, this may not reveal the behaviour of the predominant car users - the drivers - in most developed (and many developing and emerging) economies. For example, talking to the primary car users (whose presence is guaranteed, given someone has to drive) is likely to be a dominant activity for car passengers. In this circumstance, surveying existing car users in a megacity within a developing country offers two benefits. First, it is quite common for private vehicle owners to have full-time chauffeurs (professional drivers employed by the car owners) in developing countries like Bangladesh, freeing the primary car user of any driving duties. Second, the streets in such big cities (especially Dhaka and Chittagong) are heavily congested - with hours potentially lost every day stuck in traffic - encouraging travellers, including car users, to use their travel time doing something worthwhile. Therefore a 
Table 1. Summary of studies on intended time use in an FAV

\begin{tabular}{|c|c|c|c|}
\hline Parameter & Kyriakidis et al. (2015) ${ }^{a}$ & Schoettle and Sivak (2014) & $\begin{array}{l}\text { Bansal and } \\
\text { Kockelman (2017) }\end{array}$ \\
\hline Study period & July 2014 & July 2014 & June-July 2015 \\
\hline Final sample size & 4886 & 1533 & 1088 \\
\hline Geographic coverage & 109 countries & USA, UK, Australia & Texas (USA) \\
\hline Automation classification & BASt & NHTSA & NHTSA \\
\hline Question on time use & $\begin{array}{l}\text { When driving in a fully } \\
\text { automated vehicle (AV), I'll be } \\
\text { inclined in secondary tasks: }\end{array}$ & $\begin{array}{l}\text { If you were to ride in a completely self-driving } \\
\text { vehicle (L-4), what do you think you would } \\
\text { use the extra time doing instead of driving? }\end{array}$ & $\begin{array}{l}\text { Activities to be } \\
\text { performed while } \\
\text { riding in Level-4 AVs }\end{array}$ \\
\hline Would not ride in an AV & - & $22 \cdot 4$ & - \\
\hline Watch the road even not driving & - & $41 \cdot 0$ & - \\
\hline Work & - & 4.9 & $17 \cdot 4$ \\
\hline Rest/sleep & 38.5 & $7 \cdot 0$ & $18 \cdot 1$ \\
\hline Music/radio & $56 \cdot 5$ & - & - \\
\hline Mobile phone - calls/messaging & $47 \cdot 3$ & $7 \cdot 7$ & $46 \cdot 2$ \\
\hline Email check/internet surfing & $44 \cdot 3$ & - & $33 \cdot 3$ \\
\hline Watch movie/TV/play games & $39 \cdot 4$ & $7 \cdot 3$ & $27 \cdot 3$ \\
\hline Reading & $39 \cdot 2$ & $8 \cdot 3$ & $24 \cdot 5$ \\
\hline Eating/drinking & $48 \cdot 2$ & - & $56 \cdot 0$ \\
\hline Interaction with other passenger & $47 \cdot 8$ & - & $59 \cdot 5$ \\
\hline Window gazing & $47 \cdot 4$ & - & $59 \cdot 4$ \\
\hline Doing nothing & $15 \cdot 8$ & - & - \\
\hline Others & - & $1 \cdot 4$ & - \\
\hline Prefer not to respond & $9 \cdot 7$ & - & - \\
\hline Maintenance activity & - & - & $17 \cdot 5$ \\
\hline Exercise & - & - & $7 \cdot 8$ \\
\hline
\end{tabular}

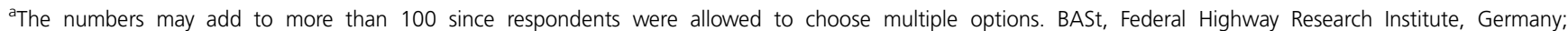
NHTSA, National Highway Traffic Safety Administration, USA

share of the responses are collected from Bangladeshi car users so as to obtain some 'revealed preference' grounding in order to understand potential travel time use in FAVs in the future.

Among various survey techniques for the study of travel time use, the travel diary, focus-group interview and questionnaire survey are the most popular ones. Questionnaire survey in online or paper form is the most convenient among these, and this approach is followed here by preparing and distributing an online questionnaire survey. Respondents were first asked about their most recent trips of different types (commute, business, leisure): the distances, the mode used (separate modal options for car passengers and drivers) and how they spent their time during that specific trip. The activities included in the tick-box options follow the existing literature on multitasking (see results tables and figure in the next section). Respondents were also asked about the activity that they spent the most time on during that trip, which is defined as the primary activity. Information was collected for both outbound and inbound trips separately for the three trip types. Respondents were then given a description of fully automated, driverless cars (along with a video link to a demonstration of an FAV) and asked to imagine the same journey to be undertaken by FAV. Questions about how they might use their travel time for that specific journey in an FAV followed. The response options for different activities are the same as before, with an additional activity of 'still watching the roadway'. Respondents were also asked about how useful they believed their travel time would be in FAVs for that specific trip type and direction. After asking about the time use in two opposite trip directions, the respondents were also asked how keen they were on using FAVs for that trip type. Finally, sociodemographic information was collected at the end of the survey.

In order to limit respondent fatigue, each respondent was asked about only two trip types (a pair from leisure, business and commute), although they were given the option to respond about the third trip type after completing the sociodemographic information, if they wished to do so. Survey participants were collected through snowballing, with initial links circulated by way of Facebook, Twitter, Linkedin and emails to peers. (Although such a convenient sample may not be representative of the population, this research does not aim to derive an average VTTS for project appraisal or predict uptake of FAVs among the population, where sample representativeness would be important.) In total, 621 individuals supplied valid responses, although the total number of valid responses across different trip types and different journey directions is 2210. Summary statistics about the respondents are presented in Table 2.

\subsection{Regression method}

Much of the present analysis utilises descriptive statistics at different aggregation levels (e.g. time use in commuting as opposed to leisure trips, outward as compared to inbound 
Table 2. Selected characteristics of survey sample (percentages are shown in parentheses)

\begin{tabular}{|c|c|c|c|}
\hline Parameter & Sample size, $N$ : number (\%) & Parameter & Sample size, $N$ : number (\%) \\
\hline Heard about FAV & & Country & \\
\hline Yes & $555(89.4)$ & Bangladesh & $218(35 \cdot 1)$ \\
\hline No & $66(10.6)$ & UK & $231(37 \cdot 2)$ \\
\hline Trip type & & USA & $108(17 \cdot 4)$ \\
\hline Commute & $410(66 \cdot 0)$ & Other countries & $64(10 \cdot 3)$ \\
\hline Business & $169(27 \cdot 2)$ & Education level & \\
\hline Leisure & $526(84 \cdot 7)$ & High school diploma & $25(4 \cdot 0)$ \\
\hline Age & & College degree & $94(15 \cdot 1)$ \\
\hline 18 to 24 & $100(16 \cdot 1)$ & Graduate degree(s) & $502(80 \cdot 8)$ \\
\hline 25 to 40 & $379(61.0)$ & Occupation & \\
\hline 41 to 54 & $102(16 \cdot 4)$ & Professional/senior managerial & $218(35 \cdot 1)$ \\
\hline 55 to 64 & $32(5 \cdot 2)$ & Middle managerial & $76(12 \cdot 2)$ \\
\hline 65 to 69 & $8(1 \cdot 3)$ & Junior managerial/clerical/supervisor & $86(13 \cdot 8)$ \\
\hline Gender & & Skilled professional & $71(11.4)$ \\
\hline Female & $224(36 \cdot 1)$ & Full-time student & $156(25 \cdot 1)$ \\
\hline Male + declined to reveal & $397(63.9)$ & Retired & $14(2 \cdot 2)$ \\
\hline
\end{tabular}

trips, etc.). Although this approach is quite common in the literature on travel time use (e.g. Lyons et al., 2007; Ohmori and Harata, 2008), there could be other substantial differences between respondents in a specific group. As such, two regressions are run to understand the drivers or factors that can affect the perceived usefulness of travel time in FAVs and the intention to use FAVs for the trip types. The two dependent variables of interest for modelling are responses to the questions, 'What per cent of your travel time will be more useful if you make the trip in a FAV?' and 'How interested are you about making your usual [commute/business/leisure] trips in a FAV?'. The responses range from 'less than $10 \%$ more useful' to 'more than $75 \%$ more useful' for the first question (five such categories) and 'not interested' to 'very interested' for the second question (four such categories). As the dependent variables (responses) have membership in discrete categories, a linear regression technique is not applicable.

Multinomial choice models are often employed to model categorical responses when there are more than two categories or responses, like here. There is, however, an order in the response categories used here (from perceived low usefulness to high usefulness of time in FAVs or low to high interest in using FAVs), and as such the better modelling options are the ordered logistic or ordered probit regression model (Green, 2012; Long and Freese, 2001). In these models, the probability of a response $Y_{i}$ falling in different categories is assumed to be governed by threshold values of an unobserved continuous variable, $y_{i}{ }^{*}$, which is a function of the dependent variables

1. $y_{i}^{*}=\alpha+\boldsymbol{X}_{i} \boldsymbol{\beta}+\varepsilon_{i}$

The resulting model is an ordered logistic model if $\varepsilon_{i}$ has a logistic distribution, and an ordered probit model if $\varepsilon_{i}$ is normally distributed. The unobserved continuous variable $y_{i}^{*}$ for the different responses is divided into the required number of observed ordered categories using thresholds values $\tau_{j}, \tau_{j-1}$, and so on. For an ordered logistic model (note that the ordered probit was also tested, but ordered logistic fits the data marginally better; both sets of results point to similar conclusions), the probability of the $i$ th observation falling within a response category $j$ is

$$
\text { 2. } \begin{aligned}
\operatorname{Pr}\left(Y_{i}=j\right)= & \frac{1}{1+\exp \left(-\tau_{j}+\boldsymbol{X}_{i} \boldsymbol{\beta}\right)} \\
& -\frac{1}{1+\exp \left(-\tau_{j-1}+\boldsymbol{X}_{i} \boldsymbol{\beta}\right)}
\end{aligned}
$$

The parameter vector $\boldsymbol{\beta}$ and threshold values $\tau$ are estimated simultaneously using the log-likelihood method. As there are more than one responses from most respondents (for different trip types), a mixed effect ordered logistic regression model was used, with random effects for the respondents. These mixed effect ordered logistic regression models are estimated using Stata.

\section{Results}

\subsection{Current use of travel time by car users}

Table 3 presents the 'revealed preference' results - namely, the activities performed by car passengers in Bangladesh - as a proxy to understanding how travel time in FAVs could be used in future. Clearly, car passengers are engaged in a range of activities and, on average, a respondent is involved in 3.6 different activities during each leg of a trip. Thinking and planning is the most popular of all activities for outbound trips: more than half $(53.7 \%)$ of the car passengers, at some point, are involved in thinking or planning, which is dominated primarily by the commute $(63.6 \%)$ and business $(64 \%)$ travellers. During outward trips for commuting and business travel a substantial number of respondents also engage in working/studying 
Table 3. All activities conducted by car passengers in Bangladesh

\begin{tabular}{|c|c|c|c|c|c|c|c|c|}
\hline \multirow[b]{3}{*}{ Activity performed by a car passenger } & \multicolumn{8}{|c|}{ Share of respondents by trip purpose and direction of travel: \% } \\
\hline & \multicolumn{2}{|c|}{ All } & \multicolumn{2}{|c|}{ Commute } & \multicolumn{2}{|c|}{ Business } & \multicolumn{2}{|c|}{ Leisure } \\
\hline & Outward & Inbound & Outward & Inward & Outward & Inward & Outward & Inward \\
\hline Working/studying & $23 \cdot 1$ & $8 \cdot 2$ & $25 \cdot 5$ & $9 \cdot 4$ & $44 \cdot 0$ & 11.5 & $11 \cdot 1$ & $5 \cdot 4$ \\
\hline Window gazing/people watching & $41 \cdot 8$ & $40 \cdot 3$ & $41 \cdot 8$ & $43 \cdot 4$ & $36 \cdot 0$ & $38 \cdot 5$ & $44 \cdot 4$ & $37 \cdot 5$ \\
\hline Thinking/planning & $53 \cdot 7$ & $35 \cdot 1$ & $63 \cdot 6$ & $41 \cdot 5$ & $64 \cdot 0$ & $50 \cdot 0$ & 38.9 & $21 \cdot 4$ \\
\hline Phone calls/messaging & $38 \cdot 1$ & $32 \cdot 8$ & $32 \cdot 7$ & $34 \cdot 0$ & $64 \cdot 0$ & $42 \cdot 3$ & $31 \cdot 5$ & $26 \cdot 8$ \\
\hline Online social media & $42 \cdot 5$ & $47 \cdot 8$ & $45 \cdot 5$ & $49 \cdot 1$ & $36 \cdot 0$ & $65 \cdot 4$ & $42 \cdot 6$ & $37 \cdot 5$ \\
\hline Reading for leisure & $9 \cdot 0$ & $6 \cdot 7$ & $10 \cdot 9$ & $5 \cdot 7$ & $8 \cdot 0$ & $7 \cdot 7$ & $7 \cdot 4$ & $7 \cdot 1$ \\
\hline Emailing/browsing internet & $33 \cdot 6$ & $33 \cdot 6$ & $40 \cdot 0$ & $37 \cdot 7$ & $48 \cdot 0$ & $50 \cdot 0$ & $20 \cdot 4$ & $21 \cdot 4$ \\
\hline Eating/drinking & $13 \cdot 4$ & $12 \cdot 7$ & $9 \cdot 1$ & 1.9 & $28 \cdot 0$ & $34 \cdot 6$ & $11 \cdot 1$ & $12 \cdot 5$ \\
\hline Sleeping/snoozing & $24 \cdot 6$ & $37 \cdot 3$ & $29 \cdot 1$ & $43 \cdot 4$ & $8 \cdot 0$ & 34.6 & $27 \cdot 8$ & $32 \cdot 1$ \\
\hline Listening to music/radio & $40 \cdot 3$ & $38 \cdot 8$ & $49 \cdot 1$ & $41 \cdot 5$ & $24 \cdot 0$ & $26 \cdot 9$ & 38.9 & $41 \cdot 1$ \\
\hline Watching video/playing games & $7 \cdot 5$ & $8 \cdot 2$ & $9 \cdot 1$ & $11 \cdot 3$ & $4 \cdot 0$ & $3 \cdot 8$ & $7 \cdot 4$ & $7 \cdot 1$ \\
\hline Talking to other passengers & $47 \cdot 0$ & $46 \cdot 3$ & $30 \cdot 9$ & $39 \cdot 6$ & $44 \cdot 0$ & $34 \cdot 6$ & $64 \cdot 8$ & $57 \cdot 1$ \\
\hline
\end{tabular}

Sample size: commute 55, business 25, leisure 55

$(25.5 \%$ and $44 \%)$. All of these shares drop significantly during the inbound leg (e.g. $9 \cdot 4 \%$ and $11 \cdot 5 \%$ for work/study and $41.5 \%$ and $50 \%$ for thinking/planning). Consequently, on the return or inbound legs, the use of social media is the most popular activity for both business travellers $(65.4 \%)$ and commuters $(49 \cdot 1 \%)$. Indeed, the use of social media is the most popular activity of car passengers during return trips $(47 \cdot 8 \%)$.

Figure 1 presents the 'primary' activities: activities the car passengers in Bangladesh spend most time on during a specific trip leg. Commuters and business travellers spend most of their time working/studying or thinking/planning (34.5\% and 60\%) during the outward leg, yet during the return leg only $17.9 \%$ of commuters and $15 \cdot 3 \%$ of business travellers engage in these 'productive' activities. This supports the notion by Lyons et al. (2007) that the travel time during outbound trips is utilised preparing for work- or business-related engagement, whereas the return trip may be associated with a depleted energy level of the traveller and accompanying relaxing or relaxed activities, which Keseru and Macharis (2018) call 'switching off'. The relatively high share of sleeping/snoozing activities during

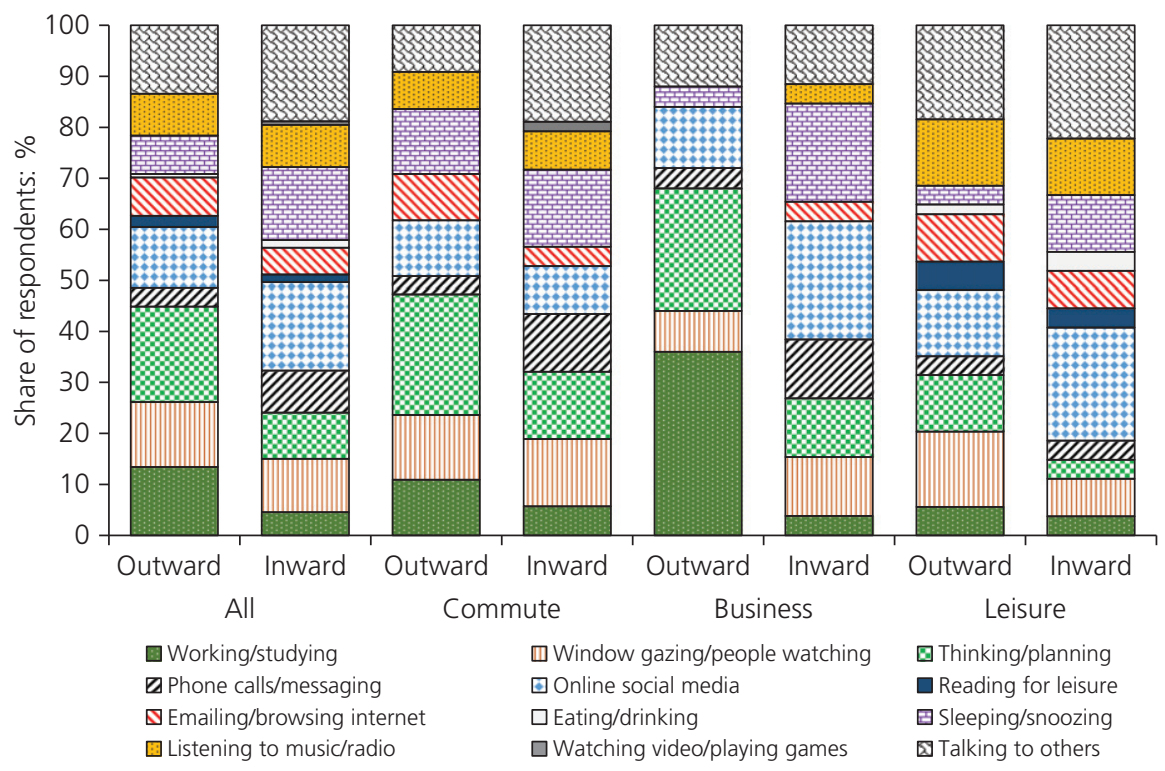

Figure 1. Primary activities on which most time was spent by car users in Bangladesh. A full-colour version of this figure can be found on the ICE Virtual Library (www.icevirtuallibrary.com) 
the return commute or business leg is likely to be the result of this switching off. The morning commute trips involve less conversation compared to the return one - a finding also observed by Gamberini et al. (2012) for underground rail in London. Overall, results from the car user sub-sample in Bangladesh clearly reveal that - when possible - the travel time in a car is used by travellers to conduct work-related or other worthwhile activities, just as in a train or a bus, as found by earlier researchers. This provides some much-needed validation for the proposition that travel time in FAVs will indeed be used for useful activities.

\subsection{Travel time use intentions in FAVs}

Nearly $90 \%$ of the sample had already heard about FAVs (Table 2). Table 4 presents all of the intended activities to be performed by the respondents during different trips in FAVs, while Figure 2 presents the primary activities on which most of the travel time will be spent. Both Tables 2 and 4 show that the largest share of respondents will continue to keep watching the roadway, indicating some lack of trust in the automated driving system. This finding is similar to that of Schoettle and Sivak (2014). Interestingly, the share of respondents watching the roadway becomes marginally smaller for return

Table 4. Intended activities (all) during travelling in an FAV - all respondents

\begin{tabular}{|c|c|c|c|c|c|c|c|c|}
\hline \multirow{3}{*}{$\begin{array}{l}\text { Stated activity on which most time } \\
\text { will be spent in an FAV }\end{array}$} & \multicolumn{8}{|c|}{ Share of respondents by trip purpose and direction of travel: $\%$} \\
\hline & \multicolumn{2}{|c|}{ All } & \multicolumn{2}{|c|}{ Commute } & \multicolumn{2}{|c|}{ Business } & \multicolumn{2}{|c|}{ Leisure } \\
\hline & Outward & Inward & Outward & Inward & Outward & Inward & Outward & Inward \\
\hline Still watching roadway & $46 \cdot 2$ & $43 \cdot 5$ & $42 \cdot 9$ & $39 \cdot 3$ & $53 \cdot 3$ & $50 \cdot 3$ & $46 \cdot 4$ & $44 \cdot 7$ \\
\hline Working/studying & $21 \cdot 8$ & $17 \cdot 3$ & $27 \cdot 6$ & $20 \cdot 7$ & $45 \cdot 0$ & $34 \cdot 3$ & $9 \cdot 9$ & $9 \cdot 1$ \\
\hline Window gazing/people watching & 31.9 & $31 \cdot 9$ & $32 \cdot 0$ & $32 \cdot 9$ & $33 \cdot 1$ & $34 \cdot 9$ & $31 \cdot 6$ & $30 \cdot 2$ \\
\hline Thinking/planning & $43 \cdot 4$ & $38 \cdot 6$ & $53 \cdot 4$ & $47 \cdot 6$ & $52 \cdot 1$ & $45 \cdot 6$ & $32 \cdot 9$ & $29 \cdot 5$ \\
\hline Phone calls/messaging & $28 \cdot 1$ & $28 \cdot 9$ & $35 \cdot 1$ & $38 \cdot 0$ & $30 \cdot 8$ & $31 \cdot 4$ & 21.9 & $20 \cdot 9$ \\
\hline Online social media & $28 \cdot 1$ & $29 \cdot 5$ & $31 \cdot 5$ & $35 \cdot 1$ & $29 \cdot 6$ & $33 \cdot 7$ & $24 \cdot 9$ & $23 \cdot 8$ \\
\hline Reading for leisure & $20 \cdot 5$ & $20 \cdot 7$ & $27 \cdot 6$ & $26 \cdot 8$ & $16 \cdot 0$ & $20 \cdot 1$ & $16 \cdot 3$ & $16 \cdot 2$ \\
\hline Emailing/browsing internet & $28 \cdot 1$ & $27 \cdot 1$ & $34 \cdot 9$ & $33 \cdot 2$ & $34 \cdot 9$ & $35 \cdot 5$ & $20 \cdot 7$ & $19 \cdot 8$ \\
\hline Eating/drinking & $16 \cdot 8$ & $16 \cdot 1$ & $15 \cdot 1$ & $14 \cdot 6$ & $26 \cdot 0$ & $24 \cdot 3$ & $15 \cdot 2$ & $14 \cdot 6$ \\
\hline Sleeping/snoozing & $16 \cdot 7$ & $21 \cdot 6$ & $18 \cdot 0$ & $22 \cdot 4$ & $17 \cdot 8$ & $27 \cdot 8$ & $15 \cdot 2$ & $19 \cdot 0$ \\
\hline Listening to music/radio & $38 \cdot 6$ & $39 \cdot 7$ & $38 \cdot 5$ & $41 \cdot 7$ & $36 \cdot 7$ & $37 \cdot 9$ & $39 \cdot 2$ & $38 \cdot 8$ \\
\hline Watching video/playing games & $7 \cdot 7$ & $8 \cdot 0$ & $8 \cdot 3$ & $9 \cdot 0$ & $5 \cdot 3$ & $5 \cdot 9$ & $8 \cdot 0$ & $7 \cdot 8$ \\
\hline Talking to other passengers & $27 \cdot 5$ & $28 \cdot 0$ & $13 \cdot 7$ & $15 \cdot 4$ & $29 \cdot 0$ & $28 \cdot 4$ & $37 \cdot 8$ & $37 \cdot 6$ \\
\hline
\end{tabular}

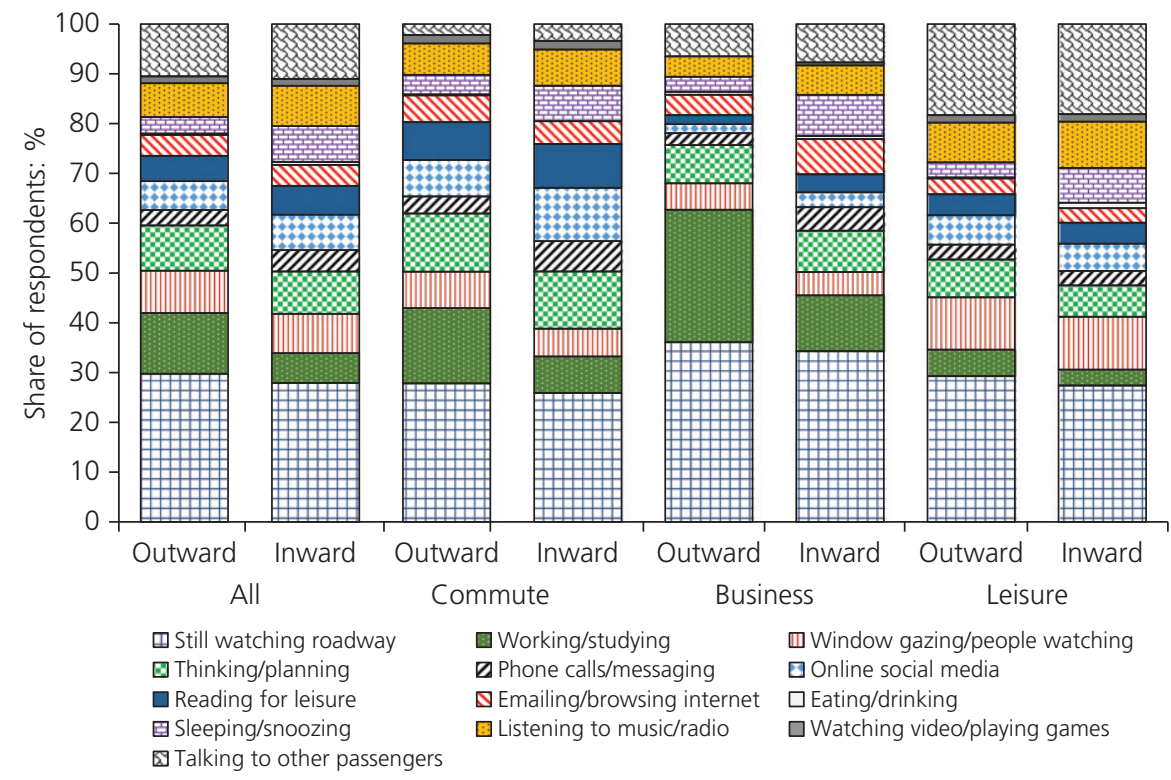

Figure 2. Primary activities on which most time is likely to be spent while in an FAV - all responses. A full-colour version of this figure can be found on the ICE Virtual Library (www.icevirtuallibrary.com) 
trips, possibly indicating some trust building during the outbound trip.

Unlike the previous studies, this study sought to understand if time in FAVs is used differently for different trip purposes and different directions of travel. Both Table 4 and Figure 2 show that intended activities in an FAV indeed vary depending on the direction of travel and trip purpose. After watching the roadway, thinking/planning remains the most popular activity in an FAV, with more than half of the respondents inclined to spend some time on this activity during outbound commute or business trips (Table 4). $27 \cdot 6 \%$ of commuters and $45 \%$ of business travellers intend to spend some time working or studying during the outbound trip, with the share dropping substantially during return trips as a result of switching off. The same pattern continues for primary activities too: nearly $12 \cdot 2 \%$ of respondents would primarily engage in working or studying during outbound trips, and the number drops to $6 \%$ for return trips. Working or studying is the second most popular 'primary' activity for outbound business and commute trips, whereas for leisure trips it is talking to other passengers. As can be expected, sleeping/snoozing is more popular for return trips compared to outbound trips.

Table 5 presents the perceived usefulness of travel time in FAVs, compared to the respondents' time in their current modes of travel. The specific question was 'What per cent of your travel time will be more useful if you make the trip in a FAV?' The responses have five levels - less than 10\%, 10-30\%, $30-50 \%, 50-75 \%$ and more than $75 \%$. Nearly two-fifths of the respondents believe that over half of their travel time will be more useful in an FAV. These responses are explored further using regression later, in Section 4.4.

\subsection{Association between current time use in chauffeured cars and future time use intentions in FAVs}

Comparison with intended use of travel time in FAVs by all respondents (Figure 2) and current time use by primary car users (as passengers) in Bangladesh (Figure 1) reveals remarkably similar patterns for primary activities, despite the obvious differences in the sample of respondents, the small sample size for Bangladeshi car passengers and quite different traffic conditions and travel patterns in Bangladesh. Although the shares of time spent in different activities are naturally quite different (e.g. there is little reading among car passengers in Bangladesh), the pattern of differences between outbound and inbound trips - especially for commute and business trips - are more often similar than not. For example, working/studying is less popular in return legs consistently across different trip purposes, indicating switching off for both the 'revealed' preference and stated intention responses. Similarly, the use of online social media or sleeping/snoozing is more popular in return legs for both current car passengers, and future FAV travellers. The ranking of current primary activities for car passengers in Bangladesh and intended primary activities in FAVs for all respondents show similarity too (Table 6). Ignoring the option 'still watching the roadway', which was not available for existing car users, the Spearman rank correlation coefficient for the intended outbound and inbound activities is 0.92 and $0 \cdot 77$, respectively, indicating a strong correlation between existing time use by car users in Bangladesh and potential time use in FAVs by all respondents. Using only Bangladeshi car user sample, the rank correlations between current primary activities and intended primary activities in FAVs are again high 0.83 and 0.89 for the two trip directions. The small subsample of 'revealed' time use activities of Bangladeshi car users thus provides a reasonable validation for the 'stated' intention observations of future potential use of travel time in FAVs.

\subsection{Usefulness of travel time in FAVs}

Table 7 presents the results of the mixed effect ordered logistic regression model for the perceived usefulness of travel time in FAVs. A positive parameter estimate means that the explanatory variable increases this usefulness. As long as the respondents are primarily involved in any activity other than watching the road, they are more likely to perceive the travel time to be more useful in the FAVs. An increase in trip duration increases the perceived usefulness of time in an FAV. However, this effect is not statistically significant at the high end of trip duration - this is possibly because most trip durations above $1 \mathrm{~h}$ are from Bangladesh, which is entered as a separate explanatory factor in the model.

The current mode of travel has a discernible effect on the perceived usefulness of travel time in FAVs. Compared to walkers, car drivers clearly find their travel time to be more useful in an FAV, which is expected as driving requires full engagement of the driver and the time otherwise spent driving

Table 5. Usefulness of travel time in FAVs and the effect of motion sickness

\begin{tabular}{|c|c|c|c|c|c|}
\hline \multirow[b]{2}{*}{$\begin{array}{l}\text { Motion } \\
\text { sickness }\end{array}$} & \multicolumn{5}{|c|}{ Share of respondents finding ... : \% } \\
\hline & $\begin{array}{l}\text { More than } 75 \% \text { time } \\
\text { more useful in FAVs }\end{array}$ & $\begin{array}{l}50-75 \% \text { time } \\
\text { more useful }\end{array}$ & $\begin{array}{c}30-50 \% \text { time more } \\
\text { useful in FAVs }\end{array}$ & $\begin{array}{c}10-30 \% \text { time more } \\
\text { useful in FAVs }\end{array}$ & $\begin{array}{l}\text { Less than } 10 \% \text { time } \\
\text { more useful in FAVs }\end{array}$ \\
\hline All & $22 \cdot 2$ & $18 \cdot 5$ & $17 \cdot 8$ & $15 \cdot 3$ & $26 \cdot 3$ \\
\hline No & $22 \cdot 6$ & $18 \cdot 2$ & $17 \cdot 8$ & $15 \cdot 8$ & $25 \cdot 6$ \\
\hline Yes & $18 \cdot 3$ & $20 \cdot 8$ & $17 \cdot 3$ & $10 \cdot 4$ & $33 \cdot 2$ \\
\hline
\end{tabular}


Table 6. Revealed and stated ranking of primary activities

\begin{tabular}{|c|c|c|c|c|c|c|}
\hline \multirow{3}{*}{$\begin{array}{l}\text { Activity on which most time is } \\
\text { or will be spent }\end{array}$} & \multirow{2}{*}{\multicolumn{2}{|c|}{$\begin{array}{c}\text { Revealed ranking of } \\
\text { current activities } \\
\text { Car passengers } \\
\text { Bangladesh }\end{array}$}} & \multicolumn{4}{|c|}{ Ranking of stated intentions in FAVs } \\
\hline & & & \multicolumn{2}{|c|}{$\begin{array}{l}\text { Car passengers } \\
\text { Bangladesh }\end{array}$} & \multicolumn{2}{|c|}{ All respondents } \\
\hline & Outbound & Inbound & Outbound & Inbound & Outbound & Inbound \\
\hline Working/studying & 2 & 9 & 2 & 7 & 1 & 7 \\
\hline Window gazing/people watching & 4 & 4 & 4 & 7 & 4 & 4 \\
\hline Thinking/planning & 1 & 5 & 5 & 3 & 3 & 2 \\
\hline Phone calls/messaging & 9 & 6 & 9 & 6 & 10 & 9 \\
\hline Online social media & 5 & 2 & 5 & 1 & 6 & 6 \\
\hline Reading for leisure & 10 & 10 & 9 & 10 & 7 & 8 \\
\hline Emailing/browsing internet & 7 & 8 & 8 & 9 & 8 & 10 \\
\hline Eating/drinking & 11 & 10 & 12 & 11 & 12 & 12 \\
\hline Sleeping/snoozing & 7 & 3 & 7 & 5 & 9 & 5 \\
\hline Listening to music/radio & 6 & 6 & 1 & 4 & 5 & 3 \\
\hline Watching video/playing games & 12 & 12 & 11 & 12 & 11 & 11 \\
\hline Talking to other passengers & 2 & 1 & 2 & 1 & 2 & 1 \\
\hline
\end{tabular}

can now be released for performing other activities in an FAV. For similar reasons cyclists also find their travel time to be more useful in FAVs. Car passengers or public transport users, however, are less likely to find the travel time in FAVs to be more useful, compared to those who walk. This possibly reflects that these user groups are not actively engaged in the act of moving (unlike walkers, cyclists or car drivers) and therefore can make some worthwhile use of their travel time currently.

Younger respondents (those 18-24 years old) are more likely to perceive their travel time to be more useful in FAVs, while those above 65 years of age are less likely to have this perception. Women are no different than men in their perception of usefulness of travel time in FAVs. Middle managers, students and skilled professionals are likely to find their travel time to be more useful in an FAV. Household size does not have an effect, but composition does: respondents with children are more likely to find their travel time to be more useful in FAVs compared to those without children. Respondents in the UK are less likely to find their travel time in FAVs to be much more useful than those in Bangladesh. This possibly reflects the very poor satisfaction with the transport system as a whole in Bangladesh (heavily crowded, unreliable public transport, poor road conditions, chronic congestion), making the potential benefits in FAVs appear large.

Motion sickness could be an important barrier in FAV adoption (Diels and Bos, 2016). Car sickness could limit the choice of activities that can be performed by FAV users, as several of the activities - especially those requiring reading a book or looking at a screen continuously - are susceptible to motion sickness, which could reduce the usefulness of time in FAVs. However, no statistically significant effect of motion sickness on the usefulness of travel time in FAVs was found through the regression. On the other hand, Table 5 presented earlier shows some differences were observed at the two ends of the responses: a smaller (larger) share of respondents with motion sickness find time to be very (slightly) useful in FAVs compared to those without motion sickness. As seen in Table 8, respondents with motion sickness intend to engage in different types of activities (less work, study or reading activities), and since the regression model already includes these activity types, the effects of motion sickness possibly occur through these activities. For example, those with motion sickness tend to engage more in thinking/planning and using phones, both of which have less influence on the usefulness of travel time in FAVs (smaller parameter estimates in Table 7) compared to working/studying, which is what the respondents without motion sickness intend to engage in more.

Unlike in ordinary least-squares linear regression, the parameters in the mixed effects ordered logistic regression do not directly represent the marginal effects of a change in the explanatory factors on the dependent variable. Table 9 presents the effects of activity type on the probability to fall within a specific group of travel time usefulness. For example, if someone spends most of their time on working or studying, they will be $13 \cdot 2 \%$ less likely to find their travel time in an FAV to be less useful, and $11.6 \%$ more likely to perceive their travel time to be very useful. On the other hand, if someone intends to spend most of their time sleeping or snoozing, they are only $7 \%$ more likely to perceive their travel time to be very useful. This also shows that the respondent's intention to work in FAVs increases the perceived usefulness of time in FAVs more than their intention to sleep or snooze in these vehicles. This indicates that the potential reduction in VoT or VTTS will be relatively higher for outbound business travel (when working is the most popular activity) compared to the return trip (when relaxing activities take place). Still, what is clear 
Table 7. Mixed effects ordered logistic regression results for perceived usefulness of travel time in an FAV

\begin{tabular}{|c|c|c|}
\hline & Coefficient & $\begin{array}{l}\text { Std } \\
\text { error }\end{array}$ \\
\hline \multicolumn{3}{|l|}{ Trip duration (base - less than $20 \mathrm{~min}$ ) } \\
\hline $20-60 \min$ & $0.45 * *$ & $0 \cdot 20$ \\
\hline $1+h$ & $0 \cdot 20$ & 0.24 \\
\hline \multicolumn{3}{|l|}{ Current mode used (base - walking) } \\
\hline Cycling & $0.99 * *$ & 0.42 \\
\hline Public transport (bus, rail, metro) & $-0 \cdot 67 * * *$ & $0 \cdot 21$ \\
\hline Motor cycle, paratransit, other & -0.63 & 0.44 \\
\hline Car as a driver & $1 \cdot 54 * \star \star$ & $0 \cdot 28$ \\
\hline Car as a passenger & $-0 \cdot 55^{\star \star}$ & 0.23 \\
\hline \multicolumn{3}{|c|}{ Most time to be spent in FAV (base - continue watching the road) } \\
\hline Working/studying & $2 \cdot 27^{* \star \star}$ & 0.33 \\
\hline Window gazing/people watching & $1.64 * * *$ & $0 \cdot 33$ \\
\hline Thinking/planning & $1 \cdot 48 * * *$ & $0 \cdot 31$ \\
\hline Phone calls/messaging & $1 \cdot 89 * * *$ & $0 \cdot 41$ \\
\hline Online social media & $1 \cdot 37 * * *$ & $0 \cdot 34$ \\
\hline Reading for leisure & $1 \cdot 62 * * *$ & 0.41 \\
\hline Emailing/browsing internet & $2 \cdot 14 * * *$ & 0.41 \\
\hline Sleeping/snoozing & $1 \cdot 41 * * *$ & $0 \cdot 39$ \\
\hline Listening to music/radio & $1 \cdot 55^{\star * *}$ & $0 \cdot 37$ \\
\hline Watching video/playing games & $1 \cdot 65^{* * *}$ & 0.61 \\
\hline Talking to other passengers & $1 \cdot 19 * * *$ & $0 \cdot 32$ \\
\hline Heard about FAVs before (base - yes): no & $1 \cdot 42 * *$ & 0.68 \\
\hline Gender (base - male): female & 0.02 & 0.44 \\
\hline \multicolumn{3}{|l|}{ Age (base $-25-40$ years) } \\
\hline 18-24 years & $1 \cdot 23^{*}$ & $0 \cdot 71$ \\
\hline $41-54$ years & 0.39 & 0.58 \\
\hline $55-64$ years & 0.05 & 0.97 \\
\hline $65+$ years & $-3 \cdot 54 * *$ & $1 \cdot 80$ \\
\hline $\begin{array}{l}\text { Education (base - non-graduate): college } \\
\text { graduate }\end{array}$ & $-1 \cdot 27 * *$ & 0.56 \\
\hline \multicolumn{3}{|l|}{ Occupation (base - senior manager) } \\
\hline Middle manager & $2 \cdot 18 * * \star$ & $0 \cdot 67$ \\
\hline Junior manager/Supervisor & 1.04 & 0.66 \\
\hline Skilled professional & $2 \cdot 46 * \star \star$ & $0 \cdot 71$ \\
\hline Retired, homemaker, others & 1.83 & 1.47 \\
\hline Student & $1 \cdot 48^{* *}$ & 0.64 \\
\hline \multicolumn{3}{|l|}{ Adults in household (base -1 person) } \\
\hline 2 persons & $-0 \cdot 33$ & 0.51 \\
\hline 3 persons & -0.93 & $0 \cdot 72$ \\
\hline $4+$ persons & $-0 \cdot 87$ & 0.66 \\
\hline Children in household (base - no): yes & $1 \cdot 37 * * *$ & 0.45 \\
\hline \multicolumn{3}{|l|}{ Country of residence (base - Bangladesh) } \\
\hline UK & $-3 \cdot 14^{* * *}$ & 0.57 \\
\hline USA & -0.78 & 0.68 \\
\hline Others & $-2 \cdot 31 * \star \star$ & $0 \cdot 75$ \\
\hline \multicolumn{3}{|l|}{ Access to personal vehicles (base - none) } \\
\hline 1 vehicle & $-0 \cdot 12$ & $0 \cdot 50$ \\
\hline $2+$ vehicles & $1 \cdot 08^{*}$ & 0.63 \\
\hline Motion sickness (base - no): yes & $-0 \cdot 58$ & 0.42 \\
\hline $\begin{array}{l}\text { Direction of trip (base - outbound): } \\
\text { inbound }\end{array}$ & $-0 \cdot 16$ & $0 \cdot 10$ \\
\hline \multicolumn{3}{|l|}{ Trip type (base - commute) } \\
\hline Business & $0 \cdot 37 *$ & $0 \cdot 21$ \\
\hline Leisure & $0 \cdot 18$ & $0 \cdot 13$ \\
\hline N & 2200 & \\
\hline Log-likelihood model & $-2455 \cdot 3$ & \\
\hline AIC & $5006 \cdot 7$ & \\
\hline
\end{tabular}

Note: asterisks indicate statistically significant ***at $99 \%$, * at $95 \%$, *at $90 \%$
Table 8. Motion sickness and intended primary activities in FAVs

\begin{tabular}{lrr} 
& \multicolumn{2}{c}{ Motion sickness } \\
\cline { 2 - 3 } Stated primary activities & No & Yes \\
Still watching the roadway & $28 \cdot 3$ & $35 \cdot 3$ \\
Working/studying & $9 \cdot 4$ & $7 \cdot 0$ \\
Window gazing/people watching & $8 \cdot 3$ & $7 \cdot 5$ \\
Thinking/planning & $8 \cdot 7$ & $10 \cdot 4$ \\
Phone calls/messaging & $3 \cdot 5$ & $6 \cdot 0$ \\
Online social media & $6 \cdot 6$ & $5 \cdot 0$ \\
Reading for leisure & $6 \cdot 0$ & $0 \cdot 0$ \\
Emailing/browsing internet & $4 \cdot 5$ & 1.5 \\
Sleeping/snoozing & $5 \cdot 4$ & $5 \cdot 0$ \\
Listening to music/radio & $7 \cdot 1$ & $10 \cdot 9$ \\
Watching video/playing games & $1 \cdot 5$ & 1.0 \\
Talking to other passengers & $10 \cdot 9$ & $10 \cdot 4$ \\
& &
\end{tabular}

from the marginal effects is that the 'productive' use of time through working or studying is not the only worthwhile use of travel time in FAVs, as often estimated in some literature (e.g. KPMG, 2015); other so-called non-productive activities such as snoozing or talking to people can be perceived as quite worthwhile, too - especially depending on trip types and directions.

\subsection{Propensity to use FAVs}

Figure 3 cross-tabulates the responses according to the perceived usefulness of time in FAVs against the interest in using FAVs for all three trip purposes in the full sample. As may be expected, those who anticipate that their travel time would be more worthwhile tend to be more interested in using FAVs. The interest in using FAVs is explored further through a mixed effect ordered logistic regression (Section 3.2) by correlating it with the potential usefulness of travel time, controlling for other factors (Table 10). Given the respondents were asked only one question about their interest to use FAVs, but were asked about the usefulness of time in FAVs separately for outgoing and return trips, two regressions are run for two trip directions.

Both the regression results for the two directions point to similar conclusions (Table 10). The result confirms the descriptive findings earlier that the interest in using FAVs increases with the perceived worthwhile use of travel time in these vehicles. In the broader context, this result supports the findings of Malokin et al. (2015) and Ettema et al. (2012) that multitasking opportunities on a transport mode increases its appeal to users.

Female respondents are less likely to be interested in using FAVs, which supports previous studies showing their consistently lower willingness to use FAVs (e.g. Schoettle and Sivak, 2014). However, it is worth noting that the female respondents are not different from the male respondents in terms of perceived usefulness of travel time in FAVs (Table 7). The lower 
Table 9. Marginal effects of activity types on perceived usefulness of time in an FAV

\begin{tabular}{|c|c|c|c|c|c|}
\hline \multirow[b]{2}{*}{$\begin{array}{l}\text { Activity on which most time } \\
\text { will be spent }\end{array}$} & \multicolumn{5}{|c|}{ Perceived usefulness of travel time in FAV } \\
\hline & $\begin{array}{c}<10 \% \text { time more } \\
\text { useful }\end{array}$ & $\begin{array}{l}10-30 \% \text { time } \\
\text { more useful }\end{array}$ & $\begin{array}{l}30-50 \% \text { time } \\
\text { more useful }\end{array}$ & $\begin{array}{l}50-75 \% \text { time } \\
\text { more useful }\end{array}$ & $\begin{array}{l}>75 \% \text { time } \\
\text { more useful }\end{array}$ \\
\hline Working/studying & $-0 \cdot 13^{* * *}$ & $-0.02 * * *$ & -0.00 & $0.04^{* * *}$ & $0 \cdot 12^{* * *}$ \\
\hline Window gazing/people watching & $-0 \cdot 10 * * *$ & $-0.02 * * *$ & 0.00 & $0.03 * * *$ & $0.08 * * *$ \\
\hline Thinking/planning & $-0.09 * * *$ & $-0.01 * * *$ & 0.00 & $0.03 * * *$ & $0.07 * * *$ \\
\hline Phone calls/messaging & $-0 \cdot 11 * * *$ & $-0.02 * * \star$ & 0.00 & $0.04 * * *$ & $0.09 * * *$ \\
\hline Online social media & $-0.08^{* \star *}$ & $-0.01 * \star$ & 0.00 & $0.03 * * *$ & $0.07 * * *$ \\
\hline Reading for leisure & $-0 \cdot 10^{* * *}$ & $-0.01 * *$ & 0.00 & $0.03 * * *$ & $0.08 * * *$ \\
\hline Emailing/browsing internet & $-0 \cdot 13^{* * *}$ & $-0.02 * \star *$ & -0.00 & $0.04 * * *$ & $0 \cdot 11 * * *$ \\
\hline Sleeping/snoozing & $-0.09 * * *$ & $-0.01 * \star$ & 0.00 & $0.03 * * *$ & $0.07 * * *$ \\
\hline Listening to music/radio & $-0.09 * * \star$ & $-0.01 * *$ & 0.00 & $0.03 * * *$ & $0.07 * \star *$ \\
\hline Watching video/playing games & $-0 \cdot 10^{* * *}$ & $-0.02 * *$ & 0.00 & $0.03^{* * *}$ & $0.08^{* *}$ \\
\hline Talking to other passengers & $-0.07 * * *$ & $-0.01 * *$ & 0.00 & $0.02 * * *$ & $0.06 * * *$ \\
\hline
\end{tabular}

Note: asterisks indicate statistically significant ***at $99 \%, * *$ at $95 \%$

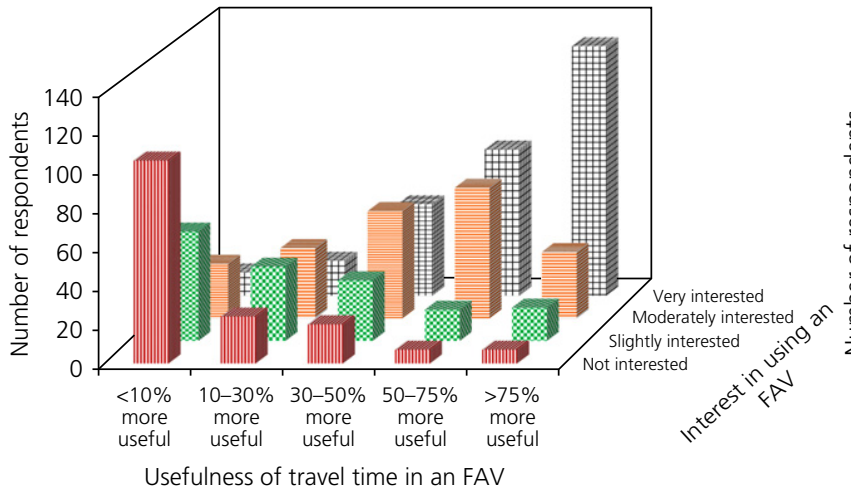

(a)

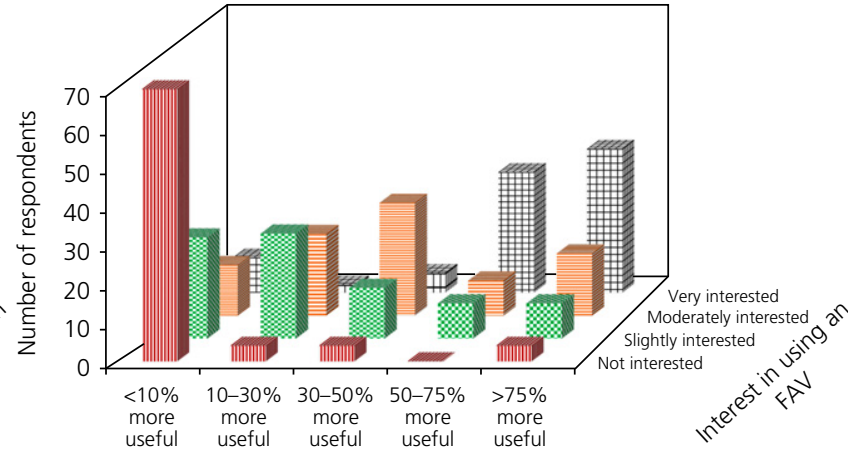

Usefulness of travel time in an FAV

(b)

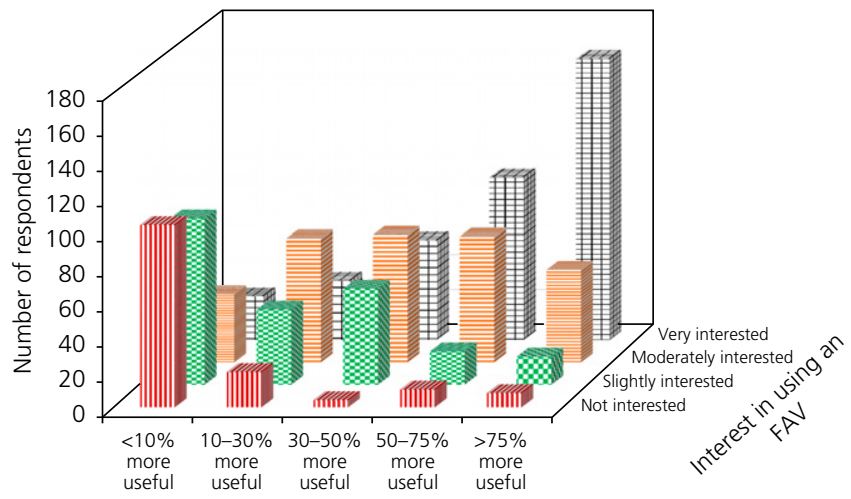

Usefulness of travel time in an FAV

(c)

Figure 3. Responses according to usefulness of travel time and interest in using FAVs: (a) commuting trips; (b) business trips; (c) leisure trips. A full-colour version of this figure can be found on the ICE Virtual Library (www.icevirtuallibrary.com)

interest among women in using FAVs therefore hints at the presence of other less utilitarian - possibly emotional - factors, as suggested by Hohenberger et al. (2016). A similar dissonance occurs for respondents with children: they are more likely to perceive their travel time to be useful in FAVs (Table 7), but no more interested in using FAVs compared to those without children (Table 10). This indicates that people with children are being more cautious in their willingness to 
Table 10. Mixed effects ordered logistic regression results for interests in using FAVs

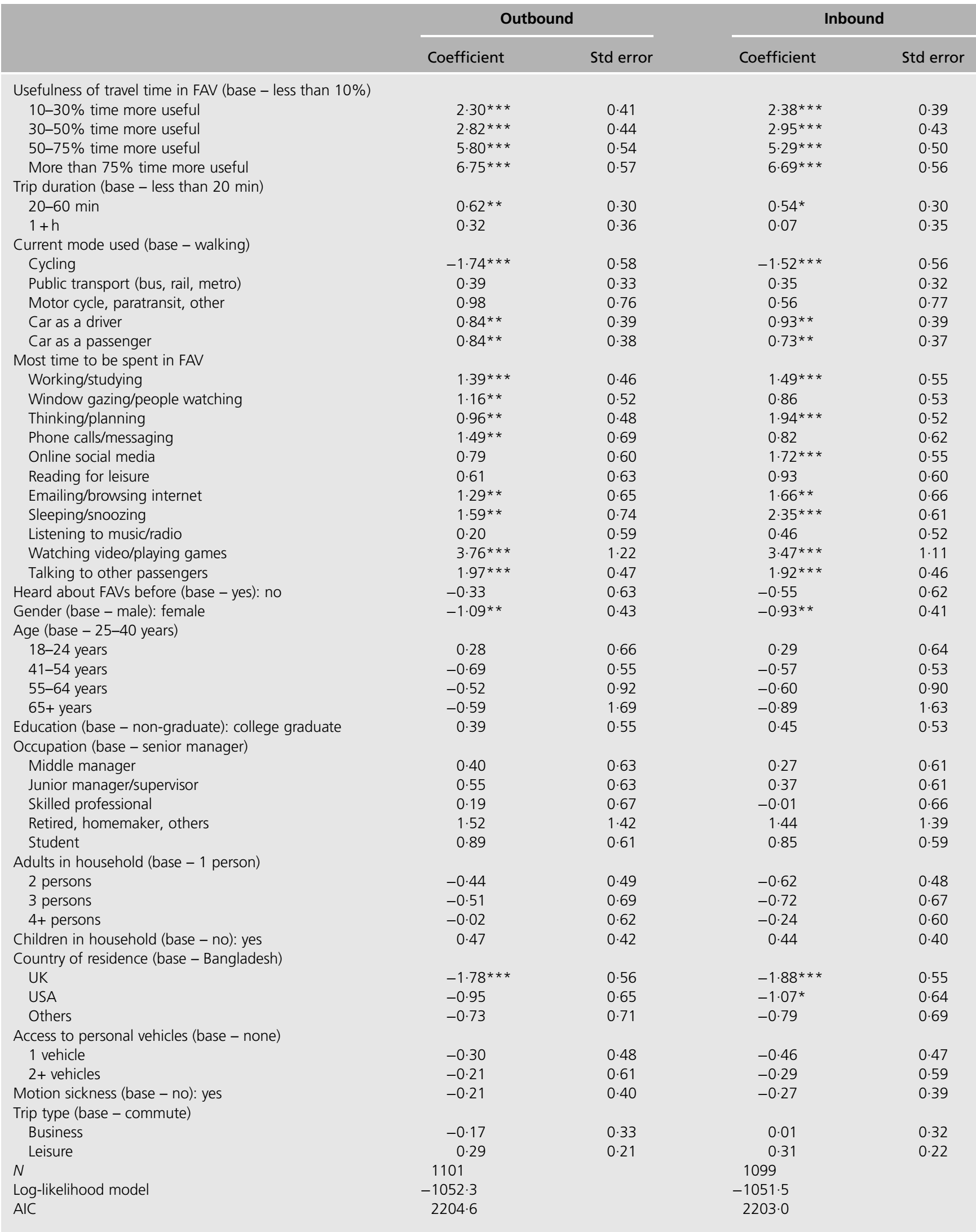

Note: asterisks indicate statistically significant ***at $99 \%$, ** at $95 \%$, * at $90 \%$ 
use FAVs, which is possibly expected given parents are known to be more risk averse (Gorlitz and Tamm, 2015).

No statistically significant difference in interests to use FAVs exists based on respondents' age, occupation, household size or access to vehicles. Note that the absence of statistical significance does not necessarily mean that these variables are not important predictors, rather it is the result of the present model structure, where many of the effects of these variables work through the perceived usefulness of time in FAVs.

Car drivers or passengers are more likely, whereas cyclists are less likely, to use FAVs. Although cyclists responded that their time will be more useful in FAVs, they are often a self-selected group who prefer cycling because of the enjoyment and health benefits; therefore their reduced willingness to use FAVs is not surprising. Respondents from the UK are less receptive to using FAVs, compared to other countries. Respondents are likely to use FAVs for longer trips, although for return trips above $1 \mathrm{~h}$, this relationship does not appear to be statistically significant for reasons mentioned before.

Motion sickness itself does not have a statistically significant parameter estimate in the model, indicating it only affects the intentions to use FAVs through reorganisation of activities and its impact on the perceived usefulness of time. In general, primary engagement in productive activities - such as working/ studying, emailing, using a phone, thinking/planning increases the likelihood of using FAVs. Respondents who primarily engage in relaxed or relaxing activities such as reading for leisure, using social media or listening to music are no more likely to use FAVs for that specific trip type (compared to those who choose to watch the roadway most of the time), except those who intend to primarily sleep or snooze, which increases their likelihood of using FAVs.

Table 11 presents the marginal effects of changes in perceived usefulness of travel time in FAVs on the propensity to use FAVs for the given trips for the outbound direction. This shows that, for example, if someone perceives that their time will be highly $(>75 \%)$ useful then the probability to be in the 'very interested' group to use FAVs will increase by $45 \cdot 3 \%$, while the probability to be in the 'not interested' group will reduce by $29 \cdot 5 \%$.
Given the survey sample in the study is not representative of the population in the three major countries sampled, the qualitative findings and relative magnitudes are more reliable, compared to absolute numerical results. For example, in the absence of strong evidence on VTTS estimates in FAVs, it may be tempting to utilise the perceived increases in the usefulness of travel time in FAVs in this study to proxy for changes in VTTS; but this can only provide a tentative and biased guidance, until rigorous VTTS estimates become available. Also, interests in using FAVs may not translate to actual use of FAVs in future, given that affordability and vehicle economics (Wadud, 2017) have an important role here. In particular, respondents in Bangladesh were quite receptive to using FAVs, which is possibly a result of existing poor transport conditions, but are less likely to afford the technology compared to the respondents in the USA or the UK.

\section{Conclusions}

The aim of this research was to investigate how travel time can be used by and be worthwhile to users while riding an FAV in future. The innovative use of chauffeur-driven cars to understand the users' travel time use is a significant contribution to understanding automation-related travel behaviour. Evidence was found that currently primary car users - car passengers driven around by chauffeurs - engage in various active and passive activities inside the vehicles, lending support to the notion that if car drivers are relieved of their driving duties they, too, will most likely engage in other worthwhile activities. Nearly every respondent showed a willingness to engage in various activities - at least for a part of the trip - when travelling in an FAV, although around one-quarter preferred to watch the roadway primarily, which possibly indicates a lack of trust in FAVs. Working or studying appear to be the second most popular activity during outbound business and commute trips, indicating possible productive use of travel time in FAVs. In general, respondents intend to 'switch off' during the return trips - especially if they are business or commuting trips - and engage in relaxed activities that do not require intense attention, which supports the revealed preference literature on time use in other modes. There is an excellent correlation between 'revealed' time use in primary car users in chauffeur-driven cars in Bangladesh and 'intended' time use in FAVs in the full sample, giving some validation to the stated intention

Table 11. Marginal effects of perceived usefulness of travel time on intention to use FAVs - outbound trips ${ }^{a}$

\begin{tabular}{|c|c|c|c|c|}
\hline \multirow[b]{2}{*}{ Perceived usefulness of travel time in FAVs } & \multicolumn{4}{|c|}{ Intention to use FAVs } \\
\hline & Not interested & Slightly interested & Moderately interested & Very interested \\
\hline $10-30 \%$ useful & $-0 \cdot 15^{* * *}$ & $-0 \cdot 04 * * *$ & $0.08 * * *$ & $0 \cdot 11 * * *$ \\
\hline $30-50 \%$ useful & $-0 \cdot 18 * * *$ & $-0.06 * * \star$ & $0.09 * * *$ & $0 \cdot 14^{* * *}$ \\
\hline $50-75 \%$ useful & $-0 \cdot 28 * \star \star$ & $-0 \cdot 17 * \star \star$ & $0.08 * * *$ & $0.37 * * *$ \\
\hline$>75 \%$ useful & $-0 \cdot 29 * * *$ & $-0 \cdot 21 * * *$ & $0.05^{\star}$ & $0.45^{* * *}$ \\
\hline
\end{tabular}

Note: asterisks indicate statistically significant ***at $99 \%$, *at $90 \%$

anbound results are nearly identical 
findings. This correlation is observed not only at the aggregate level but also at the level of trip type and journey direction.

There is evidence that the respondents believed their travel time would be more worthwhile in an FAV, compared to their current modes of transport, although the usefulness is slightly hampered by motion sickness. Respondents engaged in productive activities are more likely to find their time to be very useful compared to those engaged in non-productive (leisurely) activities, indicating the changes in VTTS in FAVs will likely depend on what type of activities people engage in. Overall, the findings on the worthwhile use of time support the hypothesis that the VTTS in an FAV will be lower compared to a manually driven vehicle, as proposed earlier by Wadud et al. (2016), Le Vine et al. (2015), Milakis et al. (2017) and Wardman and Lyons (2016), and confirmed by recent choice experiments by Kolarova et al. (2018) and de Looff et al. (2018). This has profound implications for transport project appraisal and demand forecasting. In particular, the present results also show that the intention to use FAVs is directly linked to the perceived usefulness of travel time in those cars. Implicitly, this also supports the findings of the literature on multitasking and mode choice (e.g. Malokin et al., 2015). As such, the potential increases in road travel demand and associated greenhouse gas and congestion implications resulting from widespread adoption of FAVs - one of the several FAV futures hinted at by Wadud et al. (2016), Fagnant and Kockelman (2015) or Brown et al. (2014) - appear quite plausible. Policy makers need to be aware of this possibility and act proactively to mitigate any such unintended consequences (Wadud and Anable, 2016).

The results of the present study could be useful to vehicle interior designers too. The potential engagement in different types of activities in FAVs will likely require a rethinking of the amenities and gadgets made available to FAV users. Although some of these improvements - such as, connectivity between the car and the mobile phone - are already happening, there is likely to be a need for further changes. For example, around $45 \%$ of outbound business travellers prefer to work during their travel, which may require arrangements for a worktop (along with internet connectivity). Car seat design may need to be altered to attract users who prefer to snooze or sleep in an FAV, while seating arrangements may also need to be changed to accommodate other activities. There are also differences in activity engagement for different types and directions of trips. This may warrant clever, flexible design that could be altered quickly according to user preferences, especially for shared FAVs, in order to make efficient use of the fleet (e.g. morning and afternoon commute trips have different activity splits). Just as traditional transport service providers (bus and train operators) have responded to passenger demand for wi-fi facilities in trains and buses, vehicle manufacturers or transport network companies (on-demand mobility service providers) will need to respond to a different set of needs from the users of FAVs.

\section{REFERENCES}

Bansal P and Kockelman KM (2017) Forecasting American's long term adoption of connected and autonomous vehicle technologies. Transportation Research Part A: Policy and Practice 95: 49-63.

Bansal P, Kockelman KM and Singh A (2016) Assessing public opinions of and interest in new vehicle technologies: an Austin perspective. Transportation Research Part C: Emerging Technologies 67: 1-14.

Basmajian C (2010) 'Turn on the radio, bust out a song': the experience of driving to work. Transportation 37(1): 59-84.

Batley R, Mackie P, Bates J et al. (2010) Updating Appraisal Values for Travel Time Savings. Department for Transport, London, UK.

Brown A, Gonder J and Repac B (2014) An analysis of possible energy impacts of automated vehicles. In Lecture Notes in Mobility (Meyer G and Beiker S (eds)). Springer, Cham, Switzerland, pp. 137-153.

Cyganski R, Fraedrich E and Lenz B (2015) Travel time valuation for automated driving: a use-case-driven study. Proceedings of the 94th Annual Meeting of the Transportation Research Board, Washington DC, USA.

De Looff E, Correira GHA, van Cranenburgh S, Snelder M and van Arem B (2018) Potential changes in value of travel time as a result of vehicle automation: a case study in the Netherlands. Proceedings of the 97th Annual Meeting of the Transportation Research Board, Washington DC, USA.

DfT (Department for Transport) (2015a) The Pathway to Driverless Cars. Summary Report and Action Plan. DfT, London, UK. See https://www.gov.uk/government/uploads/system/uploads/ attachment_data/file/401562/pathway-driverless-cars-summary.pdf (accessed 05/03/2019)

DfT (2015b) WebTAG: TAG Data Book. DfT, London, UK. See https://webarchive.nationalarchives.gov.uk/20140304110038/http:/ www.dft.gov.uk/webtag/documents/expert/pdf/U3_5_6-Jan-2014. pdf (accessed 07/03/2019)

Diels C and Bos JE (2016) Self-driving carsickness. Applied Ergonomics 53: $374-382$

Ettema D and Verschuren L (2007) Multitasking and value of travel time savings. Transportation Research Record 2010: 19-25.

Ettema D, Friman M, Garling T, Olsson LE and Fujii S (2012) How in-vehicle activities affect work commuters' satisfaction with public transport. Journal of Transport Geography 24: 215-222.

Fagnant D and Kockelman KM (2015) Preparing a nation for autonomous vehicles: opportunities, barriers and policy recommendations. Transportation Research Part A: Policy and Practice 77: 167-181.

Frei C, Mahmassani HS and Frei A (2015) Making time count: traveller activity engagement on urban transit. Transportation Research Part A: Policy and Practice 76: 58-70.

Gamberini L, Apahnoli A, Miotto A and Ferrari E (2012) Passengers' activities during short trips on London Underground. Transportation 40(2): 251-268.

Gorlitz K and Tamm M (2015) Parenthood and risk preferences. SSRN Electronic Journal 552, https://doi.org/10.2139/ssrn.2618442.

Green WH (2012) Econometric Analysis, 7th edn. Pearson, Harlow, UK.

Guo Z, Derian A and Zhao J (2015) Smart devices and travel time use by bus passengers in Vancouver, Canada. International Journal of Sustainable Transportation 9(5): 335-347.

Hislop D (2013) Driving, communicating and working: understanding the work-related communications behaviours of business travellers on work-related car journeys. Mobilities 8(2): 220-237. 
Hohenberger C, Sporrle M and Welpe IM (2016) How and why do men and women differ in their willingness to use automated cars? The influence of emotions across different age groups. Transportation Research Part A: Policy and Practice 94: 374-385. Jain J and Lyons G (2008) The gift of travel time. Journal of Transport Geography 16(2): 81-89.

Keseru I and Macharis C (2018) Travel-based multitasking: review of the empirical evidence. Transport Reviews 38(2): 162-183.

Kolarova V, Steck F, Cyganski R and Trommer S (2018) Estimation of the value of time for automated driving using revealed and stated preference methods. Transportation Research Procedia 31: 35-46.

KPMG (2015) Connected and Autonomous Vehicles - The UK Economics Opportunity. KPMG, London, UK. See http://www. smmt.co.uk/wp-content/uploads/sites/2/CRT036586F-Connectedand-Autonomous-Vehicles- $\%$ E2\%80\%93-The-UK-EconomicOpportu...1.pdf (accessed 05/03/2019).

Kyriakidis M, Happee R and de Winter JCF (2015) Public opinion on automated driving: results of an international questionnaire among 5000 respondents. Transportation Research Part F: Traffic Psychology and Behaviour 32: 127-140.

Laurier E (2004) Doing office work on the motorway. Theory, Culture \& Society 21(4-5): 261-277.

Le Vine S, Zolfaghari A and Polak J (2015) Autonomous cars: the tension between occupant experience and intersection capacity. Transportation Research Part C: Emerging Technologies 52: 1-14. Long S and Freese J (2001) Regression Models for Categorical Dependent Variables Using Stata. Stata Press, College Station, TX, USA.

Lyons G, Jain J and Holley D (2007) The use of travel time by rail passengers in Great Britain. Transportation Research Part A Policy and Practice 41(1): 107-120.

Mackie PJ, Fowkes AS, Wardman M et al. (2003) Value of Travel Time Savings in the UK. Department for Transport, Institute of Transport Studies, University of Leeds, Leeds, UK, Working paper 567.

Malokin A, Circella G and Mokhtarian PL (2015) How do activities conducted while commuting influence mode choice? Testing public transportation advantage and autonomous vehicle scenarios. Proceedings of the 94th Annual Meeting of the Transportation Research Board, Washington, DC, USA.

Milakis D, Snelder M, van Arem B, van Wee B and Correia G (2017) Development and transport implications of automated vehicles in the Netherlands: scenarios for 2030 and 2050. European Journal of Transport and Infrastructure Research 17(1): 63-85.

Mokhtarian PL and Salomon I (2001) How derived is the demand for travel? Some conceptual and measurement considerations. Transportation Research A: Policy and Practice 35(8): 695-719.
Ohmori N and Harata N (2008) How different are activities while commuting by train? A case in Tokyo. Tijdschrift voor Economische en Sociale Geografie 99(5): 547-561.

Rasouli S and Timmermans H (2014) Judgments of travel experiences, activity envelops, trip features and multi-tasking: A panel effects regression model. Transportation Research Part A: Policy and Practice 63: 67-75.

Redmond LS and Mokhtarian PL (2001) The positive utility of the commute; modeling ideal commute time and relative desired commute amount. Transportation 28(2): 179-205.

Schoettle B and Sivak M (2014) A Survey of Public Opinion about Autonomous and Self-Driving Vehicles in the US, the UK and Australia. University of Michigan Transportation Research Institute, Ann Arbor, MI, USA, report no. UMTRI-2014-21.

Significance, VU University Amsterdam and John Bates Services (2012) Values of Time and Reliability in Passenger and Freight Transport in the Netherlands. Ministry of Infrastructure and the Environment, The Hague, the Netherlands.

Susilo YO, Lyons G, Jain J and Atkins S (2012) Rail passengers' time use and utility assessment: 2010 findings from Great Britain with multivariate analysis. Transportation Research Record 2323: 99-109.

Timmermans HJP, van der Waerden PJHJ, Alves M et al. (2002) Time allocation in urban and transport settings: an international, inter-urban perspective. Transport Policy 9(2): 79-93.

van der Waerden P, Timmermans H and van Neerven R (2009) Extent, nature and covariates of multitasking of rail passengers in an urban corridor: a Dutch case study. Transportation Research Record 2110: 106-111.

Wadud Z (2017) Fully automated vehicles: a cost of ownership analysis to identify early adoption. Transportation Research Part A: Policy and Practice 101: 173-176.

Wadud Z and Anable J (2016) Automated Vehicles, Automatically Low Carbon? Low Carbon Vehicle Partnership and Institution of Mechanical Engineers, London, UK. See http://www.imeche.org/ policy-and-press/reports/detail/automated-vehicles-automaticallylow-carbon (accessed 07/03/2019).

Wadud Z, MacKenzie D and Leiby P (2016) Help or hindrance? The travel, energy and carbon impacts of highly automated vehicles. Transportation Research Part A: Policy and Practice 86: $1-18$.

Wardman M and Lyons G (2016) The digital revolution and worthwhile use of travel time: implications for appraisal and forecasting. Transportation 43(3): 507-530.

Zhang J and Timmermans HJP (2009) Scobit-based panel analysis of public transport users' multitasking behaviour. Transportation Research Record 2157: 46-53.

\section{How can you contribute?}

To discuss this paper, please email up to 500 words to the editor at journals@ice.org.uk. Your contribution will be forwarded to the author(s) for a reply and, if considered appropriate by the editorial board, it will be published as discussion in a future issue of the journal.

Proceedings journals rely entirely on contributions from the civil engineering profession (and allied disciplines). Information about how to submit your paper online is available at www.icevirtuallibrary.com/page/authors, where you will also find detailed author guidelines. 